\title{
Inland fish and fisheries integral to achieving the Sustainable Development Goals
}

Lynch, Abigail. J. ${ }^{*}$, Vittoria Elliott ${ }^{2}$, Sui. C. Phang ${ }^{3 \dagger}$, Julie E. Claussen ${ }^{4}$, Ian Harrison ${ }^{5}$, Karen J. Murchie $^{6}$, E. Ashley. Steel ${ }^{7}$, Gretchen L. Stokes ${ }^{8}$

${ }^{1}$ U.S. Geological Survey, National Climate Adaptation Science Center, 12201 Sunrise Valley Drive, Reston, VA 20192, USA; ajlynch@usgs.gov

${ }^{2}$ National Museum of Natural History, Smithsonian Institution; 10th St. \& Constitution Ave. NW, Washington, DC 20560, USA; vittoriaelliottemail@gmail.com

${ }^{3}$ Evolution, Ecology and Organismal Biology, The Ohio State University, Columbus, OH 43210, USA

${ }^{\dagger}$ Current address - Faculty of Business and Law, University of Portsmouth, Portsmouth PO12UP, UK; sui.phang@port.ac.uk

${ }^{4}$ Fisheries Conservation Foundation, 302 E. Green Street \#2102, Champaign IL 61825 USA; jclaussen@fishconserve.org

${ }^{5}$ Conservation International, 2011 Crystal Drive, Suite 500, Arlington, VA 22202, USA; iharrison@conservation.org 
${ }^{6}$ Daniel P. Haerther Center for Conservation and Research, John G. Shedd Aquarium, 1200

South Lake Shore Drive, Chicago, IL 60605, USA; kmurchie@sheddaquarium.org

${ }^{7}$ School of Aquatic and Fisheries Sciences, College of the Environment, University of Washington, Box 355020, Seattle, WA 98195, USA; easteel@uw.edu

${ }^{8}$ School of Natural Resources \& Environment, University of Florida, 103 Black Hall, Gainesville, FL 32611, USA; gstokes@ufl.edu

*Corresponding author 


\begin{abstract}
Inland fish provide food for billions and livelihoods for millions of people worldwide and are integral to effective freshwater ecosystem function, yet the recognition of these services is notably absent in development discussions and policies, such as the United Nations Sustainable Development Goals (SDGs). How might the SDGs be enhanced if inland fishery services were integrated into policies and development schemes? Here, we examine the relationships between inland fish, sustainable fisheries, and functioning freshwater systems and the targets of the SDGs. Our goal is to highlight synergies across the SDGs, particularly No Poverty (SDG 1), Zero Hunger (SDG 2), Clean Water and Sanitation (SDG 6), Responsible Consumption and Production (SDG 12), and Life on Land (SDG 15), that can be achieved with the inclusion of these overlooked inland fishery services.
\end{abstract}

The United Nations 2030 Agenda for Sustainable Development establishes a unified set of global aspirations [i.e., the Sustainable Development Goals (SDGs); see Figure 1 inset] that provide a roadmap for future prosperity by addressing key challenges including world poverty, hunger, disease, and illiteracy ${ }^{1}$. The 169 targets, across 17 SDGs, measured by 232 unique indicators, are ambitious and complex. Interdependencies among targets and the systems that contribute towards them mean that even the most effective efforts to address one global challenge may unintentionally exacerbate others if the efforts overlook potential wider impacts ${ }^{2-4}$. Identifying and collecting official global statistics to track progress toward each indicator is an additional challenge; data exists for some indicators, while there are significant deficits for others (see https://ourworldindata.org/sdg-tracker-update). Achieving the holistic vision of the SDGs requires coordination at multiple scales and among sectors ${ }^{5}$, as well as inclusivity of services that 
are not explicitly mentioned in the language of the SDG targets. Consideration of these overlooked services in policy decisions will not only help achieve individual targets, but can also result in mutually beneficial synergies across the SDGs.

\section{Inland fish within the SDGs}

We assert that one suite of resources conspicuously absent from the current text of the SDGs is fish $^{*}$ found in inland waters (i.e., land-locked waters ${ }^{6}$ ), inland fisheries, and freshwater systems as well as the critical services that they supply. The lack of direct mention threatens the future of these services as some decision makers may presume that inland fish are indirectly but adequately accounted for under other goals and targets. At the extreme, omission from the SDG text may lead to decision makers being unaware of the need to protect inland fish at all.

Inland fish provide food for billions and livelihoods for millions of people worldwide ${ }^{7}$ and are integral to effective freshwater ecosystem function ${ }^{8}$, yet the recognition of these services is worryingly absent in development discussions and policies ${ }^{9}$. Inland fisheries are frequently undervalued or ignored compared with other key and data-rich sectors, such as agriculture, drinking water, power, sanitation, transportation, and marine fisheries. As a result, the threats to inland fish, fisheries, and key habitats may be seen only as issues to be mitigated once other needs have been satisfied, rather than as resources with immense benefits. Failure to consider the consequences of lost services from inland fish, fisheries, and their habitats can pose unaccounted for risks, including the costs of subsidies to replace them ${ }^{10,11}$.

\footnotetext{
"We use the general term "fish" in colloquial reference but, in most instances, "fishes" is more technically accurate as many inland fishery services involve multiple species.
} 
A key challenge for including inland fish within holistic sustainable development policies is accounting for the complexity of freshwater ecosystems, the scale and dynamics of commercial and subsistence fisheries, and competing multi-sectoral freshwater users ${ }^{12}$. As a first step towards the inclusion of inland fish in these policies, we propose to highlight inland fishery services within the language of the SDG framework. This perspective aims to make it easier for decision makers and stakeholders, naturally more familiar with development terminology, to understand the critical and diverse roles of inland fish across societies worldwide, and the opportunity for inland fisheries to better support achieving sustainable development. We do acknowledge that inland fishery services are highly context specific. Our intentions here are to initiate discussions at the global scale, rather than to inform local policies.

To integrate inland fishery services within the SDG framework, (1) we used a qualitative approach to distill the collective perspective of authors with expertise in diverse inland fisheries to score a suite of nine sustainable ecosystem services associated with policies that support inland fish; and (2) assessed whether the sustainable delivery of these services contributes positively, negatively, or bidirectionally towards the attainment of individual SDG targets. To understand the resulting relationship matrix between these services and the SDGs, (3) we performed a correlation analysis among the nine services based on their relationships to the 169 SDG targets. Finally, to synthesize how SDGs relate to each service, (4) we performed a cluster analysis on the SDGs based on the correlation analysis.

Approaches on how best to address sustainability goals will differ in priority and shift in significance across countries, ranging from developing to developed, tropical to temperate, low 
population density to highly populated. Recognizing this, our aim, similar to other efforts in the sphere of linking SDGs with nature-related elements (e.g., Intergovernmental Science-Policy Platform on Biodiversity and Ecosystem Services [IPBES] Global Assessment Chapter Three ${ }^{13}$ ), is to provide decision makers with an accessible reference for designing integrated policies and development schemes that enhance the contribution of inland fish to sustainable planning, as well as to offer an approach to addressing the SDGs holistically.

Inland fishery services. We identified nine ecosystem services preserved by the sustainable management of inland fish and freshwater ecosystems, hereafter referred to as 'inland fishery services' (Table 1). This is not an analysis of services provided by inland fisheries only, but of the services emerging from approaching freshwater governance and interventions for sustainable inland fisheries. For the purposes of this study, all possible forms of inland fish on a global scale were considered, including aquaculture.

The services and reasoning included in this study were: inland fish support livelihoods and income through the sale and trade of fish and fish products from individuals or industry, and through associated jobs in the fishery ${ }^{14}$. They provide food and nutrition for billions of people globally, including protein and micronutrients ${ }^{15}$. Recreational services and individual wellbeing are supported by inland fish, including recreational fishing (e.g., charter tours, guided trips) and ecotourism ${ }^{16}$. Inland fish can contribute cultural services by providing a sense of community through cultural icons (e.g., salmon), giving identity to fishers as a source of cultural heritage, and contributing symbolically to numerous faith traditions ${ }^{17}$. Additionally, inland fish provide educational and scientific opportunities for capacity building, collaborative research, 
and training of students ${ }^{8}$. Finally, the maintenance of intact, functioning, freshwater ecosystems that support inland fish provides environmental services such as improvement of the quality of ecosystem function, enhancing biodiversity and protected areas, and regulating water quantity and quality ${ }^{18}$. The inherent need for these services to maintain sustainable fisheries motivates natural resource managers to preserve environmental integrity.

We worked from the premise that the inland fishery services we scored operate under principles of sustainability and are maintained under an ideal management scenario inclusive of the freshwater environment, in which, therefore, no solely negative interactions would occur. Sustainable inland fishery services were characterized as those that do not disrupt the ecosystem on which they rely. For example, a sustainably managed fishery safeguards against overharvest, disruptions to food web dynamics, introductions of non-native species, loss of biodiversity, and undesirable effects of fishing (e.g., " fishing down the foodweb'). Indeed, we assumed an idealized scenario in which fishery managers follow a philosophy similar to the one this study is suggesting: a holistic, ecosystem-level approach to their decisions, rather than focusing solely on fish production as a separate, unrelated entity.

The contribution of inland fishery services to the SDGs. Building from the methodology of Chapter Three of the IPBES Global Assessment ${ }^{13}$, we scored the likely contribution of the nine inland fishery services towards the 169 targets of the SDGs using a matrix format that produced a total of 1,521 scores (Supplementary Table 1). The extent to which each inland fishery service can contribute to the achievement of targets was assessed as follows: strongly positive; positive; weak or negligible; and, both positive and negative (see Table 2). We scored each of 
the 1,521 relationships through a consensus process among the eight authors who collectively possess a wide range of experiences and diverse disciplinary knowledge. Scores were given only to services with direct links to SDG targets for a total of 386 relationships. To limit complexity, we chose not to consider tangential effects in this study (i.e., those that involve inland fishery services but are principally driven by another factor, such as improvements in education due to the income gained from inland fisheries or waste reduction supported by recreational fisheries as a subset of ecotourism). Wherever published data were available to support a relationship, the reference was recorded to support our collective perspective. An initial round of scoring was conducted by individual authors according to professional expertise with particular services and the SDG targets. Initial assessments were then reviewed by the other authors and any comments were subsequently discussed to ensure that all scores were justified and defensible. To ensure consistency and check that there were no shifts due to accumulated experience during the process, we performed a secondary review of scores by each service, then by each goal. In the case of any discrepancies in either the interpretation of SDG text or in the assessment of the contribution by inland fishery services, we consulted experts from the InFish Research Network (with over 100 members from over 50 organizations in over 20 countries at the time of the exercise; infish.org) and reviewed literature to make a final consensus decision.

\section{SDGs most benefited by inland fishery services}

To identify the SDGs most benefited by inland fishery services, we aggregated the individual target scores for each service and within each SDG. To address the different number of targets across the goals (e.g., SDG 13 has five targets and SDG 17 has 19), we standardized the comparison by weighting each SDG by the total number of its targets, then, we created an 
aggregated score for all nine services for each SDG. We summarized the scores as strongly positive, positive, and bidirectional relationships (Figure 1; note that no negative-only relationships were identified in this analysis, due to our approach of evaluating only sustainable inland fishery services, as described above).

Inland fishery services have the strongest positive relationship with achieving the goals of Zero Hunger (SDG 2), Clean Water and Sanitation (SDG 6), Responsible Consumption and Production (SDG 12), and Life on Land (SDG 15). Inland fisheries provide critical sources of food, particularly to low-income, food-insecure populations ${ }^{19}$. Indeed, the effect of protecting freshwater ecosystem function for inland fish also leads to improving water quality for human use $^{20}$, yet the interaction between the health of freshwater ecosystems and their services is not sufficiently acknowledged $^{21,22}$. Explicit reference to freshwater ecosystems and their services within the SDGs is made only in targets SDG 15.1 and 15.8, which are still predominantly terrestrial focused.

Positive associations are also largely found between inland fishery services and Decent Work and Economic Growth (SDG 8), Responsible Consumption and Production (SDG 12), Climate Action (SDG 13), and Life below Water (SDG 14). Inland fisheries make substantial contributions to local and, in some cases, national economies through employment and income ${ }^{23,24}$. The harvest of wild fisheries are often considered a 'responsible' food source as there are lower environmental costs than the production of other animal proteins ${ }^{25}$. Inland capture fisheries, especially small-scale or artisanal, can have a lower carbon footprint because they are both harvested and consumed locally ${ }^{14}$. And lastly, while SDG 14 aims to improve 
marine life, freshwater influences on marine resources are substantial, particularly at the estuarine interface ${ }^{26}$.

Inland fishery services have the strongest bidirectional relationships with No Poverty (SDG 1), Gender Equality (SDG 5), and Affordable and Clean Energy (SDG 7). These bidirectional relationships demand most attention during policy and governance discussions as these sustainable inland fishery services can either contribute to or hinder achievement of these goals. In the case of SDG 1, promotion of inland fisheries and increased catch can contribute to poverty alleviation and income growth ${ }^{27}$, and open up opportunities to invest in education or alternative livelihoods. For example, increasing ecotourism opportunities through recreational fishing could provide increased opportunities for livelihoods and income, but could reduce access to the resource by locals (depending on the specific fishery). Elsewhere, gender and power dynamics in certain inland fisheries (e.g., Lake Victoria) have been observed to push women into compromising positions (e.g., sex for fish transactions) ${ }^{28}$ while in other settings inland fisheries can provide economic stability or improved community status ${ }^{29}$. Similarly, flow alterations are often categorized as 'green' providing affordable hydropower electricity, irrigation, drinking water, flood control, and recreation services, yet the associated impacts of dams are considered a major threat to freshwater ecosystems ${ }^{30}$ and can result in the destruction of fish habitat and alteration of ecosystem function ${ }^{31,32}$. Recognizing these bidirectional relationships as key opportunities for engagement, dialogue, and potential intervention could generate improved planning and more holistic development.

\section{Correlations among inland fishery services}


Assessing the correlations among the nine inland fisheries services based on the 169 assessed relationships to SDG targets (see Supplementary Methods) revealed intuitive groupings. The two resulting groups were defined as 'human well-being' and 'systems' based on the SDGs to which the services contributed most substantially (Figure 2).

Human well-being inland fishery services. We termed this group of services the 'human wellbeing group' because it comprised services related to the provision of food, livelihoods, income, and recreation, all inherently associated with quality of life (perhaps most directly, through resource exploitation). These services naturally support SDGs that are strongly linked to livelihoods and economic potential, including No Poverty (SDG 1), Zero Hunger (SDG 2), Decent Work and Economic Growth (SDG 8), and Industry, Innovation, and Infrastructure (SDG 9).

Systems inland fishery services. We termed this the 'systems group' because it is comprised of services generated by protecting freshwater systems as part of sustainable practice: water quality, water quantity, ecosystem function and biodiversity, as well as (to a lesser extent) cultural services, and fisheries science and education. The function of freshwater systems, including water quantity and quality, food web dynamics, and biodiversity, vitally support the more exploitative inland fishery services within the human well-being group. Cultural services and opportunities in science and education service, though more human-orientated than the other services in this group, are less exploitative than the services found in the human well-being group. This group of services supports SDGs that are strongly linked to water and freshwater 
ecosystems, such as Clean Water and Sanitation (SDG 6), Climate Action (SDG 13), Life Under Water (SDG 14), and Life on Land (SDG 15).

\section{Inland fishery services clusters}

The challenge of integrating inland fisheries within development frameworks is translating the diversity of services to policy-relevant language and understandable metrics. To this end, we analyzed the SDGs served by the two groups of inland fishery services (see Supplementary Methods). Understanding how these services contribute to the SDGs can underpin policy recommendations. Of the six clusters formed, we identified the three SDG clusters served by the 'human well-being' group as 'collateral,' 'monetary,' and 'consumer,' and one SDG cluster served by the 'systems' group as 'environmental' based on the SDGs most strongly represented within the clusters. The two remaining clusters lacked a substantial association with inland fishery services and were not considered further (Figure 3).

Collateral SDG cluster (bidirectional for many). The collateral cluster of targets highlights a number of areas where inland fishery services have great potential to contribute positively to SDG targets, but may have collateral consequences that negatively impact the SDGs depending on the approach and application. This diverse cluster broadly encompasses targets from ten of the goals: No Poverty (SDG 1), Quality Education (SDG 4), Gender Equality (SDG 5), Decent Work and Economic Growth (SDG 8), Reduced Inequalities (SDG 10), Sustainable Cities and Communities (SDG 11), Responsible Consumption and Production (SDG 12), Life on Land (SDG 15), Peace, Justice, and Strong Institutions (SDG 16), and Partnerships for the Goals (SDG 17). We consider identification of these interactions a particularly important result of our 
analysis. These interactions highlight opportunities to provide strong positive impacts towards achieving the goals through thoughtfully nuanced inland fishery management and policy. This would include the careful consideration of interactions between SDG goals, such as the linkages of services that fisheries provide in both reducing poverty and hunger.

Several targets within Gender Equality (SDG 5), Economic Growth (SDG 8), and Life on Land (SDG 15) stand out as having the potential for positive or negative relationships to fisheries. Interestingly, one of these goals, Life on Land (SDG 15), is the SDG that has the most relevance for inland fisheries (as the SDGs are currently interpreted) and highlights the importance of holistic planning and engagement with other sectors when implementing activities that enhance inland fishery services. In particular, the exploitation services that provide food, livelihoods, and income from inland fisheries have the potential to negatively impact targets under Life on Land (SDG 15), unless consideration is given to the impact on other services provided by the shared ecosystem (e.g., non-native introductions for food vs. native biodiversity; conservation vs. tourism development). These complex relationships emphasize the need to engage in crosssectoral collaboration and focus on synergies rather than competing objectives. By implementing a more holistic approach during the planning stage of development projects or policy deliberations, potentially negative interactions can be turned into positive ones.

Monetary SDG cluster (positive for livelihoods, income, and recreation). The SDG targets in the monetary cluster are supported by a strongly positive association to inland fishery livelihoods, income, and recreation. Jobs tied to inland fisheries, including tourism associated with recreational fisheries, directly provide income for the individuals working within the industry, 
and additionally provide taxable incomes that can strengthen economic growth in a country, distinct from subsistence livelihoods, discussed above. Less tangible benefits (which we did not score in this exercise) are associated with other services, such as outdoor recreation and its influence on the well-being and improved mental health of a population ${ }^{34-36}$ or the explicit aim of particular recreation and tourism services that support ecosystem resiliency to climate change ${ }^{37}$.

Highlighting the value of inland fisheries for all levels (i.e., subsistence, commercial, and recreational), will help governments recognize the contribution of inland fisheries to economic growth broadly (SDG 8) and especially as small-scale enterprises (SDG 9.3), in low income countries (SDG 9.2). Working within national and regional planning efforts, and emphasizing that intact ecosystems can help mitigate the effects of climate change ${ }^{38}$, can also help promote opportunities for fisheries communities to contribute to climate-change planning. For example, designing appropriate infrastructure for fisheries that addresses extreme events may further enhance the resiliency of some of the most vulnerable communities (SDG 13.1, 13.2).

Consumer SDG cluster (bidirectional for ecosystems). The SDG targets in the consumer cluster are supported by a strongly positive association to food, livelihoods, and income with bidirectional links to ecosystems. This cluster is distinguished by SDGs that relate to human well-being, namely poverty alleviation, food security, and increasing economic prosperity. The direct consumption aspect of this cluster differentiate it from the monetary cluster above focused on economic growth. The links in the consumer cluster are highly interdependent: protein and micronutrients from fish also provide essential nutrients for health ${ }^{15}$; improved health can 
increase involvement and productivity in the workforce; more work usually increases income, and thus reduces poverty and conflict (or violence) ${ }^{39}$. In this cluster, the bidirectionality for ecosystem services arises because these SDG targets have anthropocentric objectives, but ecosystem-focused management may restrict human benefits in the short-term. For example, conservation and fishery exclusion zones, which are positive for ecosystems and can restore exploited fisheries, may have negative short-term impacts on society by limiting access to the ecosystem services they provide. Invariably though, in the long-term, functioning ecosystems make many of these use-based services more sustainable and, ultimately, beneficial for human well-being.

The challenges, as well as opportunities, for the consumer SDG cluster are in finding ways to harness food, livelihoods, and income that inland fisheries provide, while ensuring conservation actions to safeguard freshwater ecosystems are implemented. Careful planning and implementation of conservation actions, such as zoning programs or monitoring of illegal fishing, as well as conducting fisheries assessments and examining the distribution of fisheries resources could support income (SDG 2.3) and fisheries conservation efforts concurrently. Actions that could both support these SDG targets and enhance the role of small-scale fisheries, include participation of fishers (particularly subsistence fishers) in policy creation and implementation, community-based conservation programs, training and capacity building for fishers, cooperative markets, and microfinance loans ${ }^{40}$. Programs that promote access to fair trade and sale of small-scale fisheries resources could increase local revenues that can be invested in social services (e.g., education, sanitation), thus further reducing extreme poverty (SDG 1.1, 1.2). Furthermore, financial benefits from 'sustainably sourced' labelling of fish 
products could encourage companies to adopt more sustainable commercial inland harvest practices (SDG 12.1-12.4) that are integrated into reporting (SDG 12.6) as well as to improve sustainable food production systems (SDG 2.4).

Environmental SDG cluster (positive for ecosystems). The SDG targets in the environmental cluster support freshwater ecosystems and services that explicitly require freshwater ecosystems to be in healthy condition. Achieving these targets requires functional ecosystems, including requisite water quantity and quality. A corollary to the maintenance of ecosystem function is the provision of inland fishery services derived from healthy freshwater ecosystems (e.g., fisheries food production, ecotourism, climate adaptation and resilience). These associations show that freshwater ecosystems and the benefits supplied via inland fishery services are central to human well-being and sustainable development ${ }^{8}$.

Actions that support progress towards the targets across the environmental cluster address the conservation of ecosystem function and environmental provisioning of water quality and flow. Several of the targets that are grouped in this cluster are associated directly with the state of freshwater ecosystems and our 'natural heritage' (e.g., SDGs 6.6, 11.4, 15.1 and 15.8) or the targets are focused on benefits that explicitly require freshwater ecosystems to be in healthy condition (SDGs 2.4, 6.1, 6.4, 13.1 and 15.5). But, inland fishery services still require more than the tangential role that they are typically assigned within integrated water resources management. This demands a full appreciation of the biophysical factors that contribute to resilient freshwater ecosystems and their fisheries, and application of ecosystem-based management approaches that encompass ecological, human, and governance aspects in 
sustainable freshwater resource management ${ }^{12}$. All of the above requires cooperation between fisheries and water sectors for efficient resource management ${ }^{41}$ and represents a need for inland fishery managers to 'join forces' with water managers to ensure essential complementary services are maintained in the development process.

\section{Boundaries and insights}

In this exercise, we applied a strict set of rules to make our analysis tractable and our results directly applicable to policy and development discussions. First, we chose to focus our analyses on inland fishery services that have been provided sustainably (i.e., current services that do not inhibit future services). There is a complex dynamic between the ecological, economic, and social aspects of inland fishery service provision ${ }^{8,42}$ and there are certainly unsustainable practices that could support achievement of some SDG targets in the short-term (e.g., exploitation from unsustainable fisheries may reduce poverty reduction and support livelihoods in select cases, but these benefits will decline in the long-term). We made a conscious choice to focus on services through sustainable management to maintain the broader vision of the SDGs. We hope the evidence from this idealized scenario will motivate both fishers and governing bodies to update current methods and incorporate sustainable harvest and operations of inland fishery services in recognition of additional SDG benefits. Indeed, the success of any policy requires appreciation of system-specific characteristics and must build upon local expertise at both governing and resource user levels.

Second, in-depth discussions during the exercise included how additional targets could be supported by each individual inland fishery service through tangential or circuitous links. We 
classified these as no clear relationship because considering them otherwise could detract from a clear enumeration of the many stronger relationships. Consider, for example, how the services of livelihoods, commercial income, and ecotourism are connected to clean water and sanitation (SDG 6); even if these services are sustainably managing their waste disposal, effluent, fuel storage, and boat gas use, they were not viewed as making an important contribution to the success of this goal ${ }^{43}$. Though a substantial task, we acknowledge greater accounting is needed to measure both positive and negative impacts, including tangential linkages, when assessing plans to achieve any specific SDG target.

Third, the exercise highlighted several pervasive inland fishery issues that often have value-laden implications, such as non-native species and aquaculture. For example, recreational fisheries and aquaculture that rely on non-native species, such as Brown Trout (Salmo trutta) or Atlantic Salmon (S. salar), can still be considered as sustainably managed (e.g., controlling waste), yet the impact on freshwater biodiversity can be severe ${ }^{44}-47$. Brown Trout has been listed as one of the World's Worst Invasive Alien Species ${ }^{48}$, while also being valued for its benefits to meeting conservation and economic goals ${ }^{49,50}$. Both purposeful and unintentional introductions of nonnative species can be detrimental to native freshwater species ${ }^{51,52}$, yet they are an integral part in some small-scale fish farms and, more commonly, in larger-scale aquaculture facilities. Similarly, the role of aquaculture as part of sustainable development ${ }^{53-55}$ and in addressing food security or economic development ${ }^{56}$ continues to be debated and assessed. Many developing countries view aquaculture as a step toward achieving food and livelihood-related SDGs but potential environmental and ecological issues associated with the industry can lead to conflicts with other goals, such as SDG 15, and sustainability of wild capture fisheries that support food 
security in many parts of the world. In this perspective, we do not attempt to make a value determination on the route policy should take but raise the point that identifying these potential conflicts is the first step towards holistic and informed policies that account for tradeoffs between goals.

Lastly, our exercise underscored the need for careful consideration of each SDG target by implementing organizations. Many of the targets, as written, are difficult to interpret and the indicators provided are not always well-aligned. Even among the authors, we found vastly different interpretations of the targets and that the associated indicators were often narrowly focused, and sometimes subjective. Thus, countries attempting to use solely the ascribed indicators to address a given target are likely to be inconsistent in what they determine as necessary activities to address the goal ${ }^{57}$. They may, at best, implement actions that do not make progress towards the target, or, at worst, implement actions that are detrimental to the goal. As targets and indicators are reconsidered, subject experts and local stakeholders need to be included to help address this issue.

\section{Lessons learned and opportunities for application}

This perspective articulates that inland fishery services make a substantial contribution to food security, poverty alleviation, livelihoods, human well-being and ecosystem function within the context of the SDG framework (Figure 1). Given the influence SDGs have on designing policy, it is vital to understand and account for the value of inland fishery services towards achieving them. The world's largest inland fisheries are in regions most in need of sustainable development; over $40 \%$ of global inland fish capture is reported from 50 low-income, food- 
deficit countries ${ }^{7}$. Inland fisheries also support overall global economic, social, and ecological importance; up to 58 million people are estimated to be employed in the inland fisheries and women comprise more than half of that workforce; indirect costs from recreational inland fisheries are valued at over USD 100 billion; and over $40 \%$ of global fish species are found in freshwater ecosystems ${ }^{7}$. These statistics underscore how critically linked inland fish and fisheries are to the SDGs even if they are absent from the SDG lexicon.

We are optimistic that the indicators used to measure progress towards targets provide the best opportunity to include inland fishery services in SDG implementation. Clarification of the intent of the goals and targets and improvement of the alignment between goals and indicators are key mandates of the High-level Political Forum on Sustainable Development to ensure progress on the 2030 Agenda (https://sustainabledevelopment.un.org/hlpf). The creation of inland indicators specific to the local environmental, social, and economic conditions, as well as considerate of the management resources and capacity, will facilitate attaining SDG goals and targets. Beyond the SDGs, realizing the importance of inland fish and fisheries should also be adopted when defining aspects of the post-2020 Global Biodiversity Framework (https://www.cbd.int/post2020/) and when reviewing the 2015 Rome Declaration: Ten Steps to Responsible Inland Fisheries ${ }^{58}$.

Powerful prospects exist for sustainably managed inland fishery services to meaningfully contribute to the success in achieving global sustainable development, particularly through Zero Hunger (SDG 2), Clean Water and Sanitation (SDG 6), and Life on Land (SDG 15; Figure 1). However, suitable integration of inland fishery services into freshwater and development policies is essential for this potential to be realized. Also, linking the objectives of the conservation of 
inland fish and the fisheries they support to the objectives of socio-economic sustainable development will be extremely important. The SDGs already form a framework for doing this; however, the existing trend is that conservation and management of freshwater resources is often overshadowed by the provision of human water security (e.g., the delivery of water, as a utility, in support of agriculture, industry, and domestic needs). These water use priorities are almost always at the cost of the environment and potentially at the cost of long-term sustainability of inland fishery services through manipulation and damage to natural habitat (e.g., flow modification, in-channel development, overfishing, pollution runoff, invasive species, and climate change $\left.{ }^{51}\right)$.

If SDGs are the solution to planning for a sustainable world, then the value of freshwater ecosystems must be elevated. Acknowledging the potential loss of biodiversity and cost to essential inland fishery services is the first step in designing sustainable, intersectoral policies that address drivers and, where necessary, identify possible compromises that either directly mitigate threats, or provide opportunities for managing risks that cannot be eliminated ${ }^{41}$. Indeed, tailoring policies and actions to the specific regional conditions where they are to be implemented is critical for sustainability. Management actions that support these services include conserving natural flow regimes, thoughtful management of upland landscapes, and well-designed ecological monitoring programs ${ }^{59}$. By recognizing the value of inland fish and the services they provide, governments and development organizations can be better poised to implement the SDGs, balance development with conservation, and create 'the future we want ${ }^{60}$.

\section{Table and figure captions}


Table 1. Sustainable inland fishery services examined in this exercise.

Table 2. An example subsection of the matrix used for scoring inland fishery services (see Table 1) with Sustainable Development Goal (SDG) targets. For the full scoring matrix, please see Supplementary Table 1. Scoring was based on the following scale: + , green, a positive relationship (the service will increase successful target implementation); +/-, yellow, there is a direct relationship, but its direction is unclear, ambiguous, or bidirectional (e.g., a U-shaped relationship); $\cdot$, there is no clear relationship (or the relationship is weak and indirect); double symbols (e.g., ++) indicate particularly strong relationships.

Figure 1. Strongly positive, positive, and bidirectional relationships between all inland fishery services (see Table 1) and each Sustainable Development Goal (SDG), weighted by the total number of targets per goal. Longer segments signify greater relative importance.

Figure 2. Correlogram of inland fishery services (see Table 1) based on their relationships to the Sustainable Development Goals. Size of circle indicates the strength of their correlation and color indicates the direction of correlation (i.e., blue = positive). Only significant correlations ( $p$ value $>0.01$ ) are shown. Two distinct groupings emerged: 1) well-being inland fishery services (commercial income; food and nutrition; livelihoods and subsistence income; recreational services); and 2) systems inland fishery services (cultural services; ecosystem function and biodiversity; educational and scientific opportunities within fisheries; regulation of freshwater quality; regulation of freshwater quantity, flow timing, and variability). 
Figure 3. Dendrogram of the SDGs based on relationships to: 1) human well-being inland fishery services and 2) systems inland fishery services. The height (y-axis) of the dendrogram represents the dissimilarity between clusters of targets. For the four clusters differentiated by at least half the maximum height, the SDG icons are listed with their size weighted by the total number of targets per goal; the remaining two clusters noted with a bar are larger groupings of SDG targets that lack a substantial association with inland fishery services and are not discussed in detail within the text.

Supplementary Table 1. Full matrix used for scoring inland fishery services (see Table 1) with Sustainable Development Goal (SDG) targets. Scoring was based on the following scale: +, green, a positive relationship (the service will increase successful target implementation); +/-, yellow, there is a direct relationship, but its direction is unclear, ambiguous, or bidirectional (e.g., a U-shaped relationship); ·, there is no clear relationship (or the relationship is weak and indirect); double symbols (e.g., ++) indicate particularly strong relationships.

\section{References}

1. UN. Transforming our World: The 2030 Agenda for Sustainable Development (A/RES/70/1). (2015).

2. Fader, M., Cranmer, C., Lawford, R. \& Engel-cox, J. Toward an Understanding of Synergies and Trade-Offs Between Water, Energy, and Food SDG Targets. Front. Environ. Sci. 6, 1-11 (2018).

3. Barbier, E. B. \& Burgess, J. C. The Sustainable Development Goals and the systems approach to sustainability. Econ. Open-Access, Open-Assessment E-Journal (2017). 
doi:10.5018/economics-ejournal.ja.2017-28

4. Bhaduri, A. et al. Achieving Sustainable Development Goals from a Water Perspective. Front. Environ. Sci. 4, 64 (2016).

5. Smith, M. S. Change the approach to sustainable development. Nature 483, 375 (2012).

6. FAO. CWP Handbook of Fishery Statistical Standards. Section G: Fishing Areas General. (2014).

7. Funge-Smith, S. Review of the State of the World Fishery Resources: Inland Fisheries. FIAF / C94, (2018).

8. Lynch, A. J. et al. The social, economic, and environmental importance of inland fish and fisheries. Environ. Rev. 24, 1-7 (2016).

9. Cooke, S. J. et al. On the sustainability of inland fisheries: Finding a future for the forgotten. Ambio 45, 753 (2016).

10. FAO. The State of World Fisheries and Aquaculture - 2018 (SOFIA). (2018).

11. Lymer, D., Teillard, F., Opio, C. \& Bartley, D. M. Freshwater fisheries harvest replacement estimates (land and water) for protein and the micronutrients contribution in the lower Mekong river basin and related countries. in Freshwater, fish, and the future: proceedings of the global cross-sectoral conference (eds. Taylor, W. W., Bartley, D. M., Goddard, C. I., Leonard, N. J. \& Welcomme, R. L.) (American Fisheries Society Press, 2016).

12. Freshwater, Fish and the Future: Proceedings of the Global Cross-Sectoral Conference. (American Fisheries Society, Food and Agriculture Organization of the United Nations, and Michigan State University, 2016).

13. Butchart, S. H. M., Miloslavich, P., Reyers, B. \& Subramanian, S. M. Chapter 3. 
Assessing progress towards meeting major international objectives related to nature and nature's contributions to people. in IPBES Global Assessment on Biodiversity and Ecosystem Services (eds. Brondizio, E. S., Settele, J., Díaz, S. \& Ngo, H. T.) (Intergovernmental Science-Policy Platform on Biodiversity and Ecosystem Services (IPBES), 2019).

14. Welcomme, R. L. et al. Inland capture fisheries. Philos. Trans. R. Soc. B-Biological Sci. 365, 2881-96 (2010).

15. Youn, S.-J. et al. Inland capture fishery contributions to global food security and threats to their future. Glob. Food Sec. 3, 142-148 (2014).

16. Cooke, S. J., Arlinghaus, R., Johnson, B. M. \& Cowx, I. G. Recreational fisheries in inland waters. in Freshwater Fisheries Ecology (ed. Craig, J. F.) 449-465 (Wiley Blackwell Science Ltd, 2015).

17. Noble, M. et al. Culturally significant fisheries: keystones for management of freshwater social-ecological systems. Ecol. Soc. 21, art22 (2016).

18. Postel, S. \& Carpenter, S. Freshwater Ecosystem Services. in Nature's Services: Societal Dependence on Natural Ecosystems (ed. Daily, G. C.) 195-214 (Island Press, 1997).

19. Fluet-Chouinard, E., Funge-Smith, S. \& Mcintyre, P. B. Global hidden harvest of freshwater fish revealed by household surveys. Proc. Natl. Acad. Sci. (2018). doi:10.1073/pnas.1721097115

20. Iovanna, R. \& Griffiths, C. Clean water, ecological benefits, and benefits transfer: A work in progress at the U.S. EPA. Ecol. Econ. 60, 473-482 (2006).

21. Brooks, E. G. E., Holland, R. A., Darwall, W. R. T. \& Eigenbrod, F. Global evidence of positive impacts of freshwater biodiversity on fishery yields. Glob. Ecol. Biogeogr. 25, 
$553-562$ (2016).

22. Holmlund, C. M. \& Hammer, M. Ecosystem services generated by fish populations. Ecol. Econ. 29, 253-268 (1999).

23. Béné, C., Macfayden, G. \& Allison, E. H. Increasing the contribution of small-scale fisheries to poverty alleviation and food security. FAO Fisheries Technical Paper (2007). doi:10.1017/CBO9781107415324.004

24. UNEP. Blue Harvest: Inland Fisheries as an Ecosystem Service. (WorldFish Center, 2010).

25. Orr, S., Pittock, J., Chapagain, A. \& Dumaresq, D. Dams on the Mekong River: Lost fish protein and the implications for land and water resources. Glob. Environ. Chang. 22, 925932 (2012).

26. Palmer, T. A., Montagna, P. A., Pollack, J. B., Kalke, R. D. \& DeYoe, H. R. The role of freshwater inflow in lagoons, rivers, and bays. Hydrobiologia 667, 49-67 (2011).

27. Béné, C. Small-scale fisheries : Assessing their contributions to rural livelihoods in developing countries. FAO Fisheries Circular No. 1008 (2006).

28. Fiorella, K. J. et al. Transactional Fish-for-Sex Relationships Amid Declining Fish Access in Kenya. World Dev. 74, 323-332 (2015).

29. Voices from African Artisanal Fisheries: Calling for an African Year of Artisanal Fisheries. (2016).

30. Ziv, G., Baran, E., Nam, S., Rodríguez-Iturbe, I. \& Levin, S. A. Trading-off fish biodiversity, food security, and hydropower in the Mekong River Basin. Proc. Natl. Acad. Sci. U. S. A. 109, 5609-14 (2012).

31. Liermann, C. R., Nilsson, C., Robertson, J. \& Ng, R. Implications of Dam Obstruction for 
Global Freshwater Fish Diversity. Bioscience 62, 539-548 (2012).

32. Winemiller, K. O. et al. Balancing hydropower and biodiversity in the Amazon, Congo, and Mekong. Science (80-. ). 351, 128-129 (2016).

33. R Core Team. R: A language and environment for statistical computing. (2018).

34. Floyd, M. F., Nicholas, L., Lee, I., Lee, J.-H. \& Scott, D. Social Stratification in Recreational Fishing Participation: Research and Policy Implications. Leis. Sci. 28, 351368 (2006).

35. Hunt, W. \& Mcmanus, A. Recreational fishing supports health and wellbeing in Western Australia. Aust. N. Z. J. Public Health 40, (2016).

36. Knopf, R. C. Recreational Needs and Behavior in Natural Settings. in Behavior and the Natural Environment. Human Behavior and Environment (Advances in Theory and Research) (eds. Altman, I. \& Wohlwill, J. F.) (Springer, 1983).

37. Elmqvist, T. et al. Response diversity, ecosystem change, and resilience. Front. Ecol. Environ. 1, 488-494 (2003).

38. Martin, T. G. \& Watson, J. E. Intact ecosystems provide the best defense against climate change. Nat. Clim. Chang. 6, 122-124 (2016).

39. Lynch, A. J. et al. Inland fisheries - Invisible but integral to the UN Sustainable Development Agenda for ending poverty by 2030. Glob. Environ. Chang. 47, 167-173 (2017).

40. FAO/DFID. Report of the consultation on integrating small-scale fisheries in poverty reduction planning in West Africa (GCP/INT/735/UK). (2003).

41. Lynch, A. J. et al. Drivers and synergies in the management of inland fisheries: Searching for sustainable solutions. in Freshwater, Fish and the Future: Proceedings of the Global 
Cross-Sectoral Conference (eds. Taylor, W. W., Bartley, D. M., Goddard, C. I., Leonard, N. J. \& Welcomme, R. L.) 183-200 (American Fisheries Society Press, 2016).

42. Olver, C. H., Shuter, B. J. \& Minns, C. K. Toward a definition of conservation principles for fisheries management. Can. J. Fish. Aquat. Sci. 52, 1584-1594 (1995).

43. Vörösmarty, C. J. et al. Ecosystem-based water security and the Sustainable Development Goals (SDGs). Ecohydrol. Hydrobiol. 18, 317-333 (2018).

44. Townsend, C. R. Invasion biology and ecological impacts of brown trout Salmo trutta in New Zealand. Biol. Conserv. 78, 13-22 (1996).

45. Penczak, T. Impact of introduced brown trout on native fish communities in the Pilica River catchment (Poland). Environ. Biol. Fishes 54, 237-252 (1999).

46. McHugh, P. \& Budy, P. Experimental Effects of Nonnative Brown Trout on the Individual- and Population-Level Performance of Native Bonneville Cutthroat Trout. Trans. Am. Fish. Soc. 135, 1441-1455 (2006).

47. Winfield, I. J. Two hearts are better than one: encouraging collaboration between freshwater fish conservation and freshwater fisheries management. Aquat. Conserv. Mar. Freshw. Ecosyst. 26, 1007-1012 (2016).

48. Lowe, S., Browne, M., Boudjelas, S. \& De Poorter, M. 100 of the World's Worst Invasive Alien Species: A selection from the Global Invasive Species Database. (2000).

49. Granek, E. F. et al. Engaging recreational fishers in management and conservation: global case studies. Conserv. Biol. 22, 1125-34 (2008).

50. Schlaepfer, M. A., Sax, D. F. \& Olden, J. D. The potential conservation value of nonnative species. Conserv. Biol. 25, 428-437 (2011).

51. Reid, A. J. et al. Emerging threats and persistent conservation challenges for freshwater 
biodiversity. Biol. Rev. (2018). doi:10.1111/brv.12480

52. Perdikaris, C., Gouva, E. \& Paschos, I. Alien fish and crayfish species in Hellenic freshwaters and aquaculture. Rev. Aquac. 2, 111-120 (2010).

53. Valenti, W. C., Kimpara, J. M., Preto, B. de L. \& Moraes-Valenti, P. Indicators of sustainability to assess aquaculture systems. Ecol. Indic. 88, 402-413 (2018).

54. Costa-Pierce, B. A. Sustainable Ecological Aquaculture Systems: The Need for a New Social Contract for Aquaculture Development. Mar. Technol. Soc. J. 44, 88-112 (2010).

55. Belton, B., Little, D. \& Grady, K. Is Responsible Aquaculture Sustainable Aquaculture? WWF and the Eco-Certification of Tilapia. Soc. Nat. Resour. 22, 840-855 (2009).

56. Béné, C. et al. Contribution of Fisheries and Aquaculture to Food Security and Poverty Reduction: Assessing the Current Evidence. World Dev. 79, 177-196 (2016).

57. Nilsson, M., Griggs, D. \& Visback, M. Map the interactions between Sustainable Development Goals. Nature 534, 320-322 (2016).

58. FAO \& MSU. Rome Declaration on Responsible Inland Fisheries: 5735E/1/06.16. (2016).

59. Beard, T. D. et al. Ecosystem approach to inland fisheries: research needs and implementation strategies. Biol. Lett. 7, 481-3 (2011).

60. UN. 66/288. The future we want. Resolution adopted by the General Assembly on 27 July 2012. 66th session. (2012).

\section{Contributions}


Conceived and designed the exercise: AJL, VE, SCP. Conducted the scoring exercise: AJL, VE, SCP, JEC, IH, KJM, EAS, GLS. Analyzed the data: AJL. Wrote the manuscript: AJL, VE, SCP, JEC, IH, KJM, EAS, GLS.

\section{Competing interests}

No funding sources had any role in the scoring exercise or in the preparation, review, or approval of this manuscript. The authors declare no competing interests.

\section{Acknowledgements}

We thank Doug Beard (USGS), Steve Cooke (Carleton U.), Ian Cowx (U. of Hull), James Dalton (IUCN), and other colleagues that we consulted as experts during this exercise; Kate Malpeli (USGS) for assistance with figures, Steve Carpenter (U. of Wisconsin) for feedback on an initial draft; Kevin Pope (USGS - U. of Nebraska - Lincoln) for conducting an internal USGS peer review; and the anonymous reviewers and journal editors for improving the manuscript. All authors are members of the InFish Research Network (infish.org). Any use of trade, firm, or product names is for descriptive purposes only and does not imply endorsement by the U.S. Government.

\section{Supplementary Methods}

Correlations among inland fishery services. We calculated the correlation of relationships to the SDG targets among inland fishery services using Pearson's correlation coefficient the $r c o r$ in the Hmisc packages in $R\left(\mathrm{v} 3.5 .1^{33}\right)$. We chose Pearson's correlation coefficient over non-parametric approaches because the underlying scores ( 0 for no relationship; 1 for positive relationship; 2 for 
strongly positive relationship; -1 for bidirectional relationship; -2 for strongly bidirectional relationship) reflect a directional and strength based relationship which is quantitative in nature. We did not test any hypotheses related to these correlation coefficients; therefore, assumptions of normality were unnecessary.

Inland fishery services clusters. We generated summary clusters from the matrix of the SDGs for each grouping using an agglomerative hierarchical clustering approach and the complete linkage method to find similar clusters. The height (y-axis) of the resulting dendrogram represents the dissimilarity between clusters of targets. Clusters differentiated by at least half the maximum height value were considered significant associations with inland fishery services. Computations were performed in R (v3.5.133) using hclust in the stats package. 


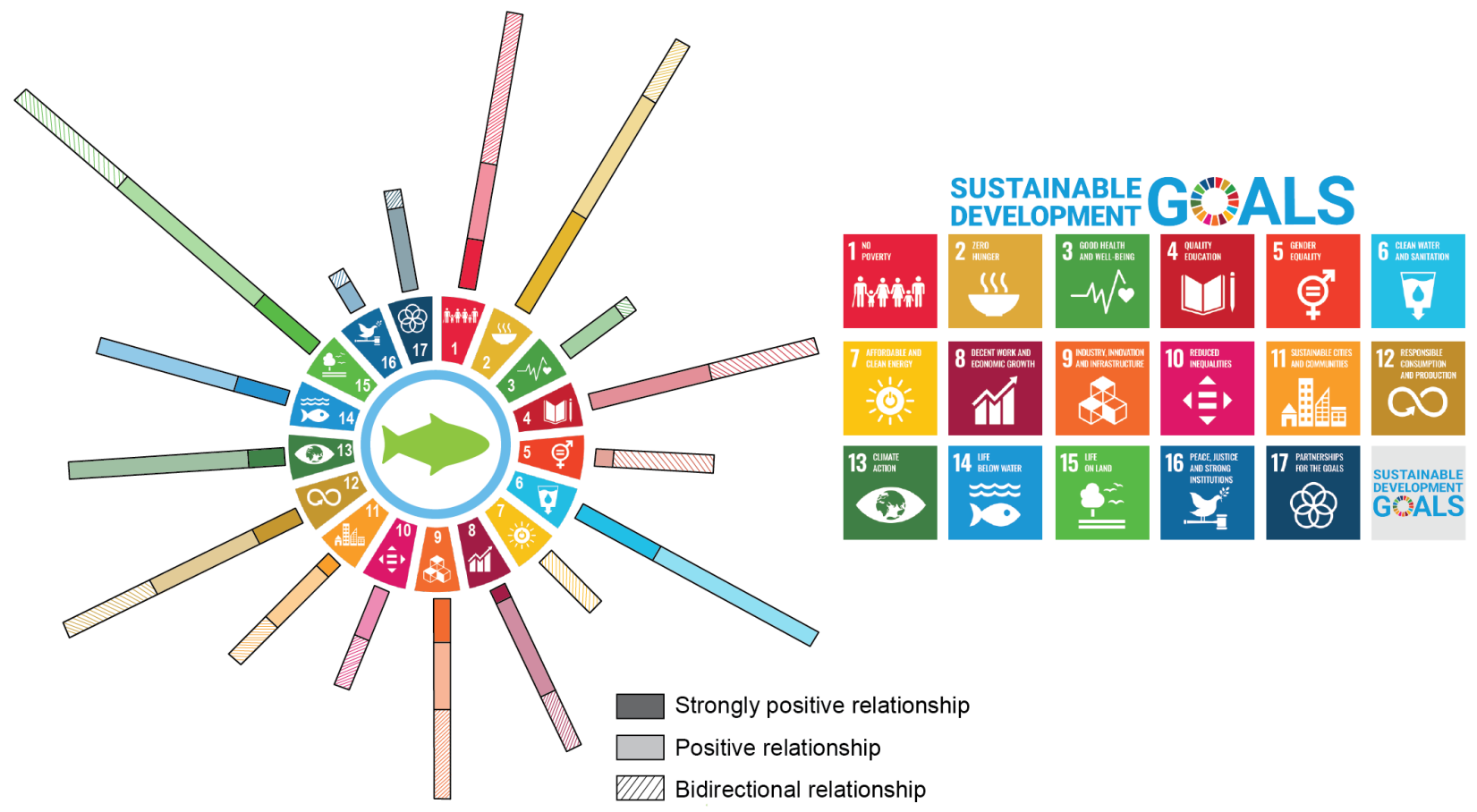

Figure 1 


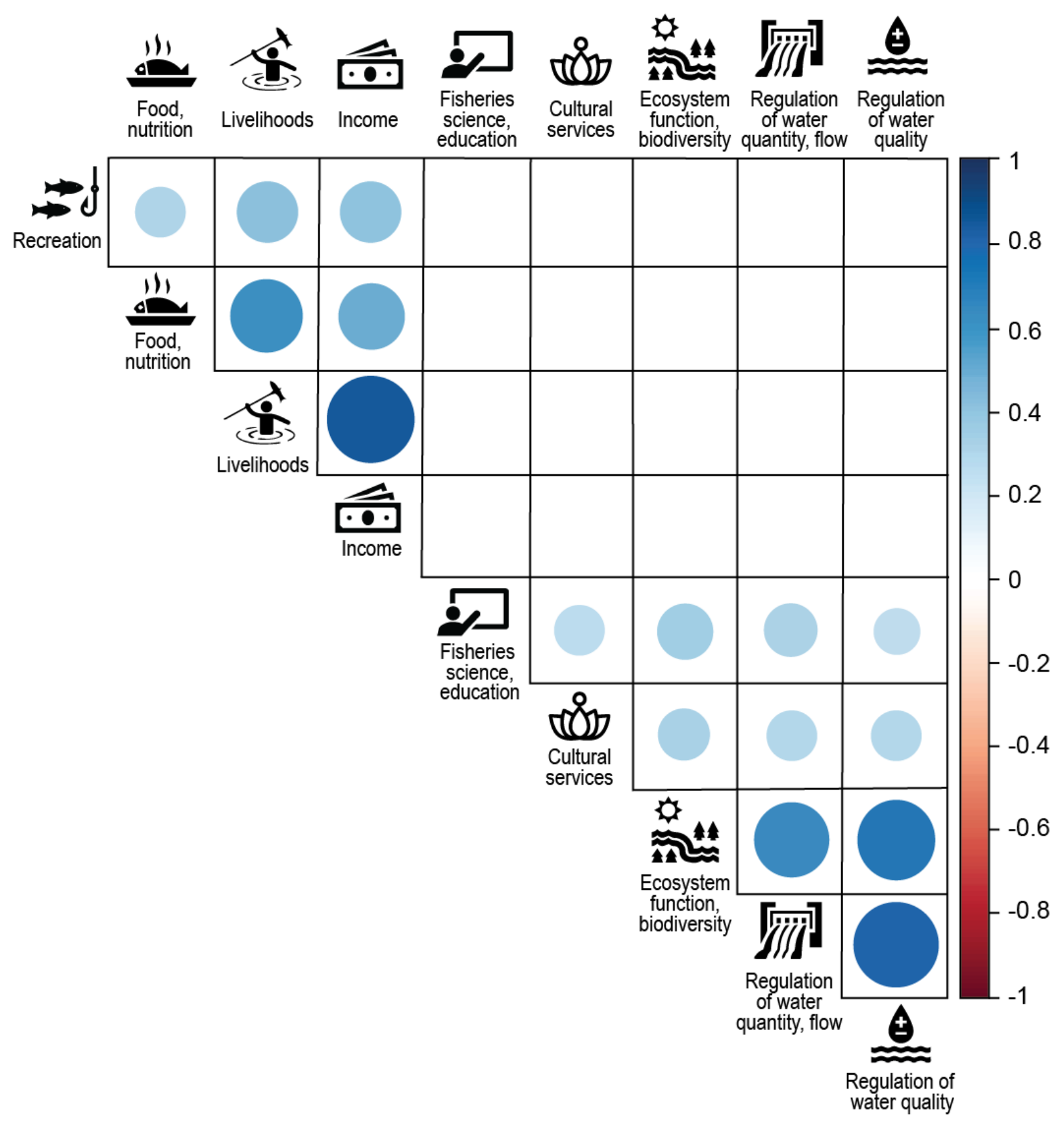

Figure 2 
1) Human well-being inland fishery services

(Commercial income; food and nutrition; livelihoods and subsistence income; recreational senvices)

-

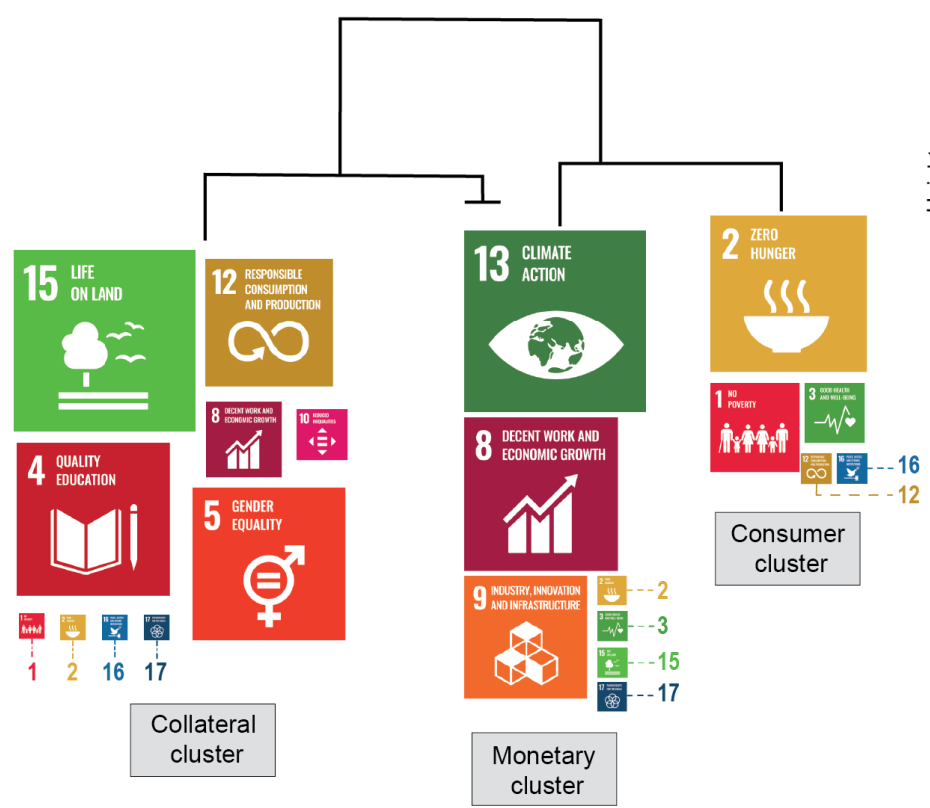

2) Systems inland fishery services

(Cultural services; ecosystem function and biodiversity; educational and scientific opportunities within fisheries; regulation of freshwater quality;

regulation of freshwater quantity, flow timing, and variability)

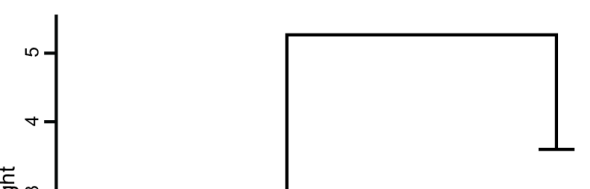

6 GIEAN WAIER

\section{AlMmat}

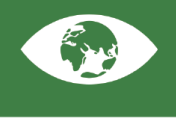

6 AND SANITATION
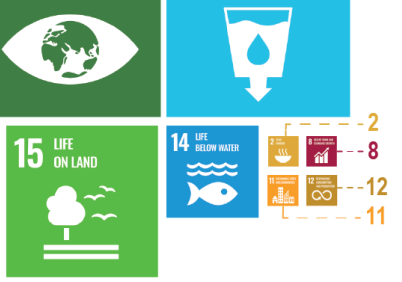

Environmental cluster

Figure 3 


\begin{tabular}{|c|c|c|}
\hline & Inland fishery service & Description \\
\hline & $\begin{array}{l}\text { Livelihoods and subsistence } \\
\text { income }\end{array}$ & $\begin{array}{l}\text { The benefits of livelihoods can be beyond subsistence (i.e., subsistence } \\
\text { income), including small-scale fishing operations and post-processing. }\end{array}$ \\
\hline & Commercial income & $\begin{array}{l}\text { Financial gain associated with commercial and sale value of wild } \\
\text { harvested, stocked, and aquacultured inland fishes. }\end{array}$ \\
\hline & Food and nutrition & $\begin{array}{l}\text { Contributions that inland fish make to food and nutrition, protein, } \\
\text { calories, and, particularly, essential micronutrients. }\end{array}$ \\
\hline & Recreational services & $\begin{array}{l}\text { Including recreational fishing industries (e.g., charter boats, guides), } \\
\text { ecotourism, and hobbyists. }\end{array}$ \\
\hline & Cultural services & $\begin{array}{l}\text { Including a sense of community; traditional values; identity as fishers; } \\
\text { and inherent value of iconic species (e.g. Threatened and Endangered } \\
\text { species). }\end{array}$ \\
\hline & $\begin{array}{l}\text { Education and scientific } \\
\text { opportunities within fisheries }\end{array}$ & $\begin{array}{l}\text { Considering fisheries science and education broadly (e.g., capacity } \\
\text { building), such as student opportunities (i.e., not only research), } \\
\text { community engagement, and public health. }\end{array}$ \\
\hline & $\begin{array}{l}\text { Ecosystem function and } \\
\text { biodiversity }\end{array}$ & $\begin{array}{l}\text { From the premise that sustainably harvested fisheries require high } \\
\text { functioning ecosystems and biodiversity contributes to ecosystem } \\
\text { function. }\end{array}$ \\
\hline & Regulation of freshwater quality & $\begin{array}{l}\text { From the premise that sustainably harvested inland fisheries require } \\
\text { high freshwater quality. }\end{array}$ \\
\hline & $\begin{array}{l}\text { Regulation of freshwater quantity, } \\
\text { flow timing, and variability }\end{array}$ & $\begin{array}{l}\text { From the premise that sustainably harvested inland fisheries require } \\
\text { natural-like freshwater quantity, flow, and variability. }\end{array}$ \\
\hline
\end{tabular}

\section{Table 1}

